\title{
Correction to: Analytical Model of the Transport of Aerosol Particles in a Circular Hole Inside a Porous Medium
}

\author{
S. K. Zaripov ${ }^{1}$ (D) O. V. Soloveva ${ }^{2}$ E. V. Skvortsov ${ }^{1}$
}

Received: 7 September 2021 / Accepted: 10 September 2021 / Published online: 20 October 2021

(c) Springer Nature B.V. 2021

\section{Correction to: Transp Porous Med (2015) 107:141-151 https://doi.org/10.1007/s11242-014-0429-x}

The original publication of the article includes the incorrect approximate functions (28), (29). The correct approximate functions are:

$$
\begin{gathered}
\delta(\tau)=\delta_{1}(\tau)+\delta_{2}(\tau) \tau+\delta_{3}(\tau) \tau^{1.5}, \delta_{1}=1.489, \delta_{2}=0.165, \delta_{3}=-0.358 \\
\lambda(\tau)=\lambda_{1}(\tau)+\lambda_{2}(\tau) \tau+\lambda_{3}(\tau) \tau^{1.5}, \lambda_{1}=3.575, \lambda_{2}=-7.647, \lambda_{3}=4.9647
\end{gathered}
$$

Publisher's Note Springer Nature remains neutral with regard to jurisdictional claims in published maps and institutional affiliations.

The original article can be found online at https://doi.org/10.1007/s11242-014-0429-x.

S. K. Zaripov

shamil.zaripov@kpfu.ru

1 Kazan Federal University, Kazan 420008, Russia

2 Kazan State Power Engineering University, Kazan 420066, Russia 